\title{
O DIREITO DOS POVOS ORIGINÁRIOS NO BRASIL: ANÁLISE A PARTIR DO DOCUMENTÁRIO “ÍNDIO CIDADÃO?”
}

\author{
Florisbal de Souza Del'Olmo* \\ Giselda Siqueira da Silva Schneider ${ }^{* *}$
}

Resumo: A investigação objetiva analisar o Direito dos Povos Originários no Brasil, a partir da narrativa cinematográfica, tendo por fonte o documentário “Índio Cidadão?”. Utiliza-se como método de pesquisa: a descritiva, a documental, a revisão bibliográfica e a análise crítica. A abordagem estrutura-se em: a) apresentar o tema central e os pontos principais do documentário; b) apontar e explicar as questões de ordem jurídica veiculadas; e c) identificar os dados sociais, confrontando-os com a noção de cidadania da Constituição de 1988. Conclui-se: Povos nativos permanecem na "invisibilidade" social ante a cultura dominante estabelecida, sofrendo constantes violações de direitos.

Palavras-chave: Direito. Povos Nativos. Documentário. Cidadania.

\section{THE RIGHT OF NATIVE PEOPLE IN BRAZIL: ANALYSIS FROM THE DOCUMENTARY "INDIAN CITIZEN?"}

\begin{abstract}
The goal of the investigation is analyze the Right of Native People in Brazil from the cinematographic narrative, having as source the documentary "Indian Citizen?" It is used as methodology of this study: Descriptive research, documental, literature review and critical review. The approach is structured in: a) presenting the central theme and main points of the documentary; b) point out and explain the legal issues raised; and c) identify the social data, confronting them with the notion of citizenship of the 1988 Constitution. One concludes: Native People remains in social "invisibility", according to dominant culture, suffering constant violations of rights.
\end{abstract}

Keywords: Right. Native People. Documentary. Citizenship.

\footnotetext{
* Pós-Doutor em Direito (UFSC). Doutor (UFRGS) e Mestre em Direito (UFSC). Especialista em Direito e em Educação. Graduação em Odontologia e Direito. Professor do Programa de Pós-Graduação Stricto Sensu Mestrado e Doutorado em Direito da URI, Santo Ângelo, RS. Líder do Grupo de Pesquisa registrado no CNPq Tutela dos Direitos e sua Efetividade. Coordenador do Projeto de Pesquisa Direito Internacional do Trabalho e o resgate da dignidade e da cidadania. E-mail: florisbaldelolmo@gmail.com.

** Mestra em Direito e Justiça Social pela Universidade Federal do Rio Grande (PPGD/FURG). Mestra em História pela Universidade de Passo Fundo (PPGH/UPF). Especialista em Direito do Trabalho e Previdenciário pelo Centro Universitário Ritter dos Reis. Bacharela em Ciências Jurídicas e Sociais pela Pontifícia Universidade Católica do Rio Grande do Sul (PUC/RS). Professora e Advogada. Membro do Grupo de Pesquisa registrado no CNPq Tutela dos Direitos e sua Efetividade. E-mail: giseldasiqueira@hotmail.com.
}

Revista de Sociologia, Antropologia e Cultura Jurídica | e-ISSN: 2526-0251 | Maranhão | v. 3 | n. 2 | p. 45 - 65 | Jul/Dez. 2017. 


\section{INTRODUÇÃO}

É consenso na doutrina afirmar o Direito enquanto fato ou fenômeno social, que, por sua vez, irá retratar determinada realidade social. Não obstante, ao longo da história da colonização do Brasil, o Direito que então se constitui, nitidamente influenciado pela visão eurocêntrica, desprezou flagrantemente "realidades sociais", como a dos diferentes povos que habitavam o país antes da chegada do homem europeu. Logo, a visão de mundo para o Brasil, trazida a partir da colonização, por muito tempo permitiu a manutenção de regras jurídicas que conciliavam os interesses da elite em detrimento do “direito” existente no interior dos grupos étnicos presentes na realidade brasileira, permitindo graves violações, verdadeiras barbáries para a exploração das riquezas contidas nas terras.

Juridicamente, apenas em 1988 os distintos grupos étnicos sobreviventes à dura e cruel ação do colonizador ao longo dos anos serão incluídos na acepção de cidadania, tendo direitos reconhecidos. Esses distintos povos, chamados na legislação constitucional de “índios” ou “indígenas”, conviveram anteriormente com uma legislação elaborada no período dos governos militares, hoje ainda em vigor, a Lei n. 6.001/1973, conhecida como Estatuto do Índio, que idealizava a integração dos povos à nação brasileira, com a consequente eliminação gradual de seus costumes e elementos culturais. Em síntese, havia naquele período, como menciona Ailton Krenak (2015), um trabalho sistemático de diluição das identidades das tribos indígenas.

Comenta-se pouco, na literatura jurídico-acadêmica, acerca da fundamental participação dos povos indígenas na Constituinte de 1987, o que é compreensível, tendo em vista a perpetuação da ideia dominante de que tais povos haviam sido completamente dizimados ou, ainda, que os mesmos não teriam conhecimento, tampouco participação sobre a condução das questões políticas no país, dentre outros possíveis motivos. A partir de tal problemática, elenca-se por hipótese que, passados vinte e nove anos de vigência da Constituição Cidadã, tais “realidades sociais”, a dos povos originários, ainda parecem permanecer na invisibilidade social no Brasil.

Revista de Sociologia, Antropologia e Cultura Jurídica | e-ISSN: 2526-0251 | Maranhão | v. 3 | n. 2 | p. 45 - 65 | Jul/Dez. 2017. 
Dados recentes do Instituto Brasileiro de Geografia e Estatísticas, o IBGE, alertam para o crescimento da população indígena em desproporção (para mais) em relação ao crescimento da população não indígena (para menos), o que enseja atenção do Estado na forma de políticas públicas voltadas para as necessidades de tais grupos. Nesse contexto, será também pela arte que esses povos encontraram uma forma de expressar sua visão de mundo, sua pluralidade, tradições, costumes e, inclusive, suas reivindicações. Narrativas de diversas etnias ganham espaço no cinema o que demonstra a força da presença indígena no Brasil. Somente no ano de 2016 ocorreram em cidades brasileiras amostras, bienais e festivais de cinema indígena, protagonizado e dirigido pelos mesmos.

Dessa forma, justifica-se a presente investigação que, ao utilizar a narrativa cinematográfica enquanto fonte de pesquisa, objetiva analisar o Direito dos Povos Originários no Brasil, verificando sua efetividade no plano fático. Assim, pela metodologia da pesquisa descritiva, aliada a pesquisa documental e a revisão bibliográfica pertinente, bem como o estudo numa perspectiva crítica, utiliza-se o documentário “Índio Cidadão?” para análise. A abordagem estrutura-se em: apresentar o tema central e os pontos principais do documentário (1); apontar e explicar as questões de ordem jurídica veiculadas (2); e, por fim, identificar os dados sociais, confrontado-os com a noção de cidadania da Constituição de 1988 (3).

\section{O DOCUMENTÁRIO “ÍNDIO CIDADÃO?”}

O Documentário “Índio Cidadão?” (DF, 2014, 52’), do diretor Rodrigo Siqueira Arajeju, com duração de 52 minutos, é um recurso audiovisual que utiliza a oralidade tão presente na tradição e cultura indígena para pautar o tema da cidadania indígena. Pela narrativa de dirigentes indígenas, retrata dois momentos históricos de grande importância político-jurídica dos povos no Brasil: a trajetória de luta por reconhecimento de direitos que culmina na Constituinte de 1987; e as mobilizações nacionais em Brasília em 2013 pela | p. 45 - 65 | Jul/Dez. 2017. 
manutenção dos direitos constitucionais. O filme evidencia também as graves violações de direitos humanos sofridas pelos Kaiowá Guarani, conforme destaca a sinopse:

\begin{abstract}
A União das Nações Indígenas, em ato de desobediência civil contra a tutela do Estado, coordena movimento político de participação popular na Constituinte (1987/88). Vinte e cinco anos depois, o Movimento Indígena ocupa o Plenário da Câmara dos Deputados e realiza Mobilização Nacional em Defesa dos Direitos Constitucionais ameaçados pelo próprio Congresso Nacional. A Nação Kaiowá e Guarani, alheia ao Direito e à Justiça, revela a narrativa testemunhal do genocídio indígena em marcha no estado do Mato Grosso do Sul (DF, 2014, 52').
\end{abstract}

O recorte temporal retratado pela narrativa, 1987 a 2013, começa no contemporâneo, com a Mobilização Nacional Indígena em Defesa da Constituição Federal em 2 de outubro de 2013, destacando a manifestação dos povos em Brasília para ingressar no Congresso Nacional e de imediato sofrendo a repressão policial, e depois volta para o ano da instalação da Assembleia Nacional Constituinte em fevereiro de 1987. Logo, esse período (1987 a 2013) não será tratado de maneira linear, pelo contrário, será de maneira concomitante e complementar, sempre fazendo a remissão ao antes e depois da Constituição de 1988, ou seja, da luta pelo reconhecimento de direitos ao momento atual, passados 25 anos da vigência da Constituição (considerando o ano do filme, que é 2014) e dos desafios para implementação e manutenção dos direitos. É o que se percebe nas palavras iniciais do filme: "é uma conquista né, não um privilégio não [...]; derramou sangue antes de ser aprovada a Constituição Federal” (DF, 2014, 52’). Em seguida, o título na forma de indagação, “Índio Cidadão?”, é apresentado para a reflexão que será propiciada no desenrolar.

Logo, o documentário rememora as mobilizações das Nações Indígenas na década de 1980 e que culminam na Constituinte de 1987, demonstrando que tais povos foram presença indiscutível em Brasília nessa ocasião, pois que muitos grupos saíram direto de suas aldeias para encontrar outros, pela primeira vez em Brasília, como aponta a narrativa cinematográfica, que é realizada do início ao fim pela liderança Kaiowá Guarani Valdelice Veron, do Grande Conselho Aty Guasu. 
Outras lideranças e seus depoimentos também constroem a narrativa: o cacique Raoni Metuktire, Ailton Krenak, Davi Yanomami, Alvaro Tukano e Sonia Guajajara, entre outras figuras públicas que defendem as causas dos povos originários presentes na realidade brasileira. Recorda-se, inclusive, de Mário Juruna, primeiro e único parlamentar federal indígena na história do Brasil. Eleito pelo Rio de Janeiro em 1982, durante a marcha de oposição à ditadura militar no país, cacique xavante, natural do Estado do Mato Grosso, fora uma figura implacável na defesa dos direitos dos povos indígenas do Brasil, em especial para recuperar as terras dos xavantes, e nem por isso deixou de sentir o estigma de ser "diferente" naquela conjuntura para defender “os diferentes” e subalternizados. Juruna era tido enquanto uma personalidade exótica, pelo jeito de falar, pelo jeito de ser xavante.

Destaca-se a figura de Ailton Krenak, verdadeira voz dos povos indígenas na Assembleia Constituinte, ao discursar em 4 de setembro de 1987, deixando na história o gesto simbólico (expressão cultural) de pintar o rosto de preto, enquanto defendia a proposta de Emenda Parlamentar ao Projeto de Constituição, visando tratar do Capítulo das Populações Indígenas:

Sr. Presidente, srs. Constituintes, eu, com a responsabilidade de, nesta ocasião, fazer a defesa de uma proposta das populações indígenas à Assembleia Nacional Constituinte, havia decidido, inicialmente, não fazer uso da palavra, mas de utilizar parte do tempo que me é garantido para defesa de nossa proposta numa manifestação de cultura com o significado de indignação - e que pode expressar também luto pelas insistentes agressões que o povo indígena tem diretamente sofrido [...]. Tivemos a honra de, desde a instalação dos trabalhos da Assembleia Nacional Constituinte, sermos convidados a participar dos trabalhos na Subcomissão dos Negros, Populações Indígenas, Pessoas Deficientes e Minorias. [...] mais tarde, tivemos também a oportunidade de participar da instalação dos trabalhos da Comissão da Ordem Social. Ao longo desse período, a seriedade com que trabalhamos e a reciprocidade de muitos dos srs. Constituintes permitiriam a construção, a elaboração de um texto que provavelmente tenha sido o mais avançado que este país já produziu com relação aos direitos do povo indígena (KRENAK, 2015, p. 32-33, grifo nosso). 
Ocorre que os direitos dos povos indígenas foram reconhecidos, não exatamente nos termos propostos pelo movimento das Nações Indígenas, a começar pelo Capítulo na Constituição de 1988, que se intitulou “Dos Índios” e não das “Populações Indígenas”. No entanto, bem narra o documentário que da promulgação da Constituição Federal, passados os primeiros cinco anos, os indígenas, embora os direitos territoriais assegurados na lei, na realidade fática não usufruíram desse direito. E atualmente, ponderação realizada pelo filme, é de que mesmo após 25 anos de vigência da Constituição paradigmática, por reconhecer direitos aos povos, por admitir os indígenas enquanto os primeiros habitantes da terra, "povos originários”, ainda há muito a fazer para que o direito ao território seja efetivado.

Ademais, retrata a dura realidade vivida pelas populações indígenas, uma verdadeira perseguição ao serem expulsos de suas terras, inclusive com violações de direitos, como a própria morte de indígenas, como acontece no Estado do Mato Grosso do Sul, especialmente com a Nação Kaiowá Guarani. Os Kaiowá Guaranis vivem uma situação de extrema violação de direitos humanos, um verdadeiro genocídio, já que além de expulsos, muitos foram mortos para "forçar" saírem de suas terras, como relata Valdelice Veron, que teve seu pai brutalmente morto numa das ações de “despejo”, em 16 de outubro de 2001, coordenada por grandes fazendeiros e ruralistas naquele Estado.

Pela análise, configuram-se dois momentos importantes: a partir do período que marca a conquista de direitos para os povos - a Assembleia Constituinte de 1987, com a consequente promulgação da Constituição Federal de 1988 - ao ano de 2013, com as Mobilizações Indígenas em defesa da manutenção de direitos constitucionais, pois a Proposta de Emenda Constitucional, a PEC 215, em tramitação no Congresso Nacional ameaça retroceder nas conquistas constitucionais. Em ambos os momentos, percebe-se que os povos indígenas possuem clareza quanto aos seus direitos, e que em suas coletividades possuem ativa atuação política ao reivindicar a manutenção desses direitos em Brasília.

Enfim, o documentário traz à tona uma realidade social desconhecida e ainda invisível para o Brasil, sendo fonte relevante para conhecimento desses grupos étnicos, suas percepções acerca da vida e do direito e, mais, revela aspectos de um processo histórico que se 
desconhece (da participação desses grupos na Constituinte de 1987), e que ao conhecer desconstrói estereótipos e mitos acerca da participação e visão dos povos sobre a condução política e jurídica do país, especialmente no tocante aos seus direitos, que, embora positivados, carecem de efetivação e sofrem ameaças legislativas. A seguir, apontam-se as questões de ordem jurídica veiculadas no documentário.

\section{O DIREITO DOS POVOS ORIGINÁRIOS NO BRASIL}

A Constituição Federal Brasileira de 1988, ao superar as perspectivas assimilacionistas e integracionistas, inaugura no constitucionalismo brasileiro uma fase de reconhecimento e respeito às diversidades étnicas e culturais presentes na realidade multicultural do país. $\mathrm{O}$ Estado brasileiro ao prever o direito à igualdade garante o direito à diferença, o que inclui o direito à diferença de culturas. A referida Constituição consagra um capítulo específico para a proteção dos direitos indígenas. Entre os direitos permanentes e coletivos assegurados aos indígenas pode-se sintetizar:

\begin{tabular}{l}
\hline CONSTITUIÇÃO DA REPÚBLICA FEDERATIVA DO BRASIL DE 1988 \\
\hline \multicolumn{1}{|c|}{ CAPÍTULO VIII DOS ÍNDIOS (arts. 231 a 232) } \\
\hline Direito à organização social, costumes, línguas, crenças e tradições; \\
\hline $\begin{array}{l}\text { Direitos originários e imprescritíveis sobre as terras que tradicionalmente ocupam, } \\
\text { consideradas inalienáveis e indisponíveis; }\end{array}$ \\
\hline $\begin{array}{l}\text { Obrigação da União de demarcar as terras indígenas, proteger e fazer respeitar todos os } \\
\text { bens nelas existentes; direito à posse permanente sobre essas terras; }\end{array}$ \\
\hline Proibição de remoção dos povos indígenas de suas terras, salvo em casos excepcionais; \\
\hline Usufruto exclusivo das riquezas do solo, dos rios e dos lagos nela existentes; \\
\hline Uso de suas línguas maternas e dos processos próprios de aprendizagem; \\
\hline $\begin{array}{l}\text { Proteção e valorização das manifestações culturais, que passaram a integrar o patrimônio } \\
\text { cultural do país. }\end{array}$ \\
$\begin{array}{l}\text { Fonte: CONSTITUIÇÃO DA REPÚBLICA FEDERATIVA DO BRASIL DE } 1988 . \\
\text { Elaboração Própria. }\end{array}$
\end{tabular}

Revista de Sociologia, Antropologia e Cultura Jurídica | e-ISSN: 2526-0251 | Maranhão | v. 3 | n. 2 | p. 45 - 65 | Jul/Dez. 2017. 
De igual maneira, outra grande inovação diz respeito ao reconhecimento da capacidade postulatória dos índios, suas comunidades e organizações para a defesa de seus interesses e direitos, sendo prerrogativa do Ministério Público o dever de garantir e intervir em todos os processos judiciais que tenham relação com tais direitos e interesses. Aliás, a competência para julgar os litígios sobre direitos indígenas é da Justiça Federal, consoante estabelece o art. 109, inciso XI, da Constituição Federal.

No art. 231 da Constituição são previstos os direitos originários sobre as terras tradicionalmente ocupadas pelos índios. Dentre os direitos reconhecidos, o direito à terra, configura-se como uma das questões mais delicadas, pois o território para o indígena está acima de qualquer valor econômico, representando a base e o suporte de sua vida social. Encontra-se a definição de Terras Indígenas no próprio dispositivo constitucional:

São terras tradicionalmente ocupadas pelos índios as por eles habitadas em caráter permanente, as utilizadas para suas atividades produtivas, as imprescindíveis à preservação dos recursos ambientais necessários a seu bemestar e as necessárias a sua reprodução física e cultural, segundo seus usos, costumes e tradições (BRASIL, 1988, grifo nosso).

Krenak (2015), em seu depoimento em O eterno retorno do encontro, demonstra acerca da percepção do indígena em relação ao território:

O território tradicional de meu povo vai do litoral do Espírito Santo até entrar nas serras mineiras, entre o vale do Rio Doce e São Mateus. Mesmo que hoje só tenhamos uma reserva pequena no médio Rio Doce, quando penso no território do meu povo, não penso naquela reserva de 4 mil hectares, mas num território onde a nossa história, os contos e as narrativas do meu povo vão acendendo luzes nas montanhas, nos vales, nomeando os lugares e identificando na nossa herança ancestral o fundamento da nossa tradição. Esse fundamento da tradição, assim como o tempo do contato, não é um mandamento ou uma lei que a gente segue, nos reportando ao passado, ele é vivo como viva a cultura, ele é vivo como é dinâmica e viva qualquer sociedade humana. É isso que nos dá a possibilidade de sermos contemporâneos uns dos outros, quando algumas das nossas famílias ainda acendem o fogo friccionando uma varinha no terreiro da casa ou dentro de casa, ou um caçador se deslocando na floresta e fazendo o seu fogo assim - autossustentável (KRENAK, 2015, p. 161, grifo nosso).

Revista de Sociologia, Antropologia e Cultura Jurídica | e-ISSN: 2526-0251 | Maranhão | v. 3 | n. 2 | p. 45 - 65 | Jul/Dez. 2017. 
Dessa forma, evidencia-se o valor da terra para o indígena, distante da atribuição comercial e econômica que o território possui na cultura ocidental capitalista. Será o território para o indígena o lugar onde sua vida está pautada, diretamente ligada aos seus ancestrais, onde apreende e transmite de geração em geração a tradição, os saberes. Esse sentimento de pertencimento que o indígena tem em relação à terra, comumente chamada de “mãe”, embasa e preenche o conceito de direito ao território, expresso na legislação pátria.

O direito constitucional reconhecido sobre as terras ocupadas caracteriza-se como um direito originário, inalienável, indisponível e imprescritível, tal como consta no art. 232, parágrafo $4^{\circ}$, da Constituição Federal, competindo à União a demarcação e a proteção desses bens. Dessa forma, significa dizer que os direitos sobre tais terras ocupadas operam desde sempre para o antes e o depois, o futuro. E ainda que não dependem de reconhecimento formal. O legislador constituinte em 1987, visando à efetivação do direito do índio à terra, previu atos que envolvem a demarcação das terras indígenas e que são de fundamental importância para a sobrevivência física e cultural de tais comunidades. Destaca Ana Valéria Araújo (2004) que sempre que uma população indígena ocupar tradicionalmente uma área caberá à União, consoante o art. 231, promover o reconhecimento, com a declaração do caráter indígena da respectiva terra, realizando o procedimento de demarcação física dos seus limites, com o objetivo de garantir a sua proteção.

Pela redação do art. 67 do Ato das Disposições Constitucionais Transitórias, “A União concluirá a demarcação das terras indígenas no prazo de cinco anos a partir da promulgação da Constituição” (BRASIL, 1988), o que não aconteceu. Segundo Dalmo Dallari, a explicação passa por compreender que uma das marcas do tempo atual "é a tentativa de subordinar todos os direitos, interesses e valores fundamentais da pessoa humana a objetivos econômicos”, logo, segundo o jurista, sob o pretexto da globalização, grupos econômicos de grande poder juntamente com os governos submissos a eles, passam a impor aos povos "regras ditadas por 
seus interesses e apelidadas de 'leis de mercado', desprovidas de ética e de legitimidade democrática” (DALLARI, 2000, p. 31).

De acordo com o Conselho Indigenista Missionário, num levantamento a respeito das reivindicações de terras (em 2013), constatava que das 1.047: “apenas 38\% estão regularizadas. Cerca de 30\% das terras estão em processo de regularização e 32\% sequer tiveram iniciado o procedimento de demarcação por parte do Estado brasileiro” (BUZATTO, 2013, p. 11). E sem qualquer litígio judicial, existem 30 processos de demarcação em áreas já identificadas pela Fundação Nacional do Índio, a FUNAI, indicando que não haveria nenhuma pendência para a efetivação da demarcação das terras, faltando apenas procedimentos administrativos. Isso sem mencionar as polêmicas em torno da temática das terras indígenas, em julgamentos recentes pelo Supremo Tribunal Federal, como a tese do marco temporal, uma das condicionantes da Raposa-Serra do Sol, que defende que os índios só teriam direito às terras efetivamente ocupadas em 5 outubro de 1988, na data da promulgação da Constituição Federal.

Nesse contexto, surge a Proposta de Emenda à Constituição 215/2000, que pretende incluir dentre as competências exclusivas do Congresso Nacional, a aprovação da demarcação das terras tradicionalmente ocupadas pelos índios e a ratificação das demarcações já homologadas, estabelecendo critérios e procedimentos de demarcação por regulamentação de lei (BRASIL, 2000). A PEC 215 quer modificar o art. 49 e o art. 231 da Constituição Federal e, da mesma forma, alterar o Decreto 1.775/96, que define o procedimento para demarcação da terra indígena. Assim, os deputados federais, caso aprovada a PEC 215, irão decidir sobre a demarcação das terras indígenas, a titulação das terras quilombolas e a criação das unidades de conservação da natureza (parques, reservas florestais, estações ecológicas, por exemplo).

À PEC 215 foram acrescidas 11 proposições legislativas (de autoria de diferentes deputados) cujo conteúdo, em todas elas, é unânime, no sentido de reduzir os direitos indígenas assegurados pelo Estado em 1988: PEC 579/2002, PEC 257/2004, PEC 275/2004, PEC 319/2004, PEC 156/2003, PEC 37/2007, PEC 117/2007, PEC 161/2007, PEC 291/2008, PEC 411/2009, PEC 415/2009. Logo, evidencia-se um movimento “anti-indígena” no Poder 
Legislativo, o que fere os princípios contidos na Constituição Cidadã e em tese a própria democracia brasileira. Juristas, como Dallari, pronunciaram-se publicamente a respeito da inconstitucionalidade da referida proposta de Emenda Constitucional, pois que fere o princípio da separação dos poderes e pelo entendimento de que o direito ao território assegurado ao indígena não depende de demarcação, pois que tal procedimento administrativo mantém sua importância apenas para delimitação das terras indígenas.

Apontadas as questões de ordem jurídica que aparecem no documentário, passa-se ao exame dos dados sociais relativos ao tema, bem como a relação com à noção de cidadania a partir da Constituição de 1988.

\section{OS POVOS ORIGINÁRIOS NA ATUALIDADE E A CIDADANIA}

Pelos dados do IBGE, Censo de 2010, a população indígena soma 896,9 mil indígenas. Entre os que se declararam indígenas mais de 520 mil estão vivendo em áreas rurais e em torno de 357 mil residem nas cidades. Oportuno destacar que o termo índio comporta em torno de 305 etnias diferentes, com o reconhecimento de 274 línguas indígenas (IBGE, 2015). O Censo do IBGE somente a partir de 1991 incluiu os indígenas na pesquisa demográfica nacional (FUNAI, 2015).

Pelo referido Censo grande parte da população indígena concentra-se na região Norte do país, em torno de 342 mil indígenas, e a menor concentração na região Sul, em torno de 78,8 mil índios (IBGE, 2015). Por sua vez, dados do Instituto Socioambiental, organização da sociedade civil brasileira, fundada em 1994, "para propor soluções de forma integrada a questões sociais e ambientais com foco central na defesa de bens e direitos sociais, coletivos e difusos relativos ao meio ambiente, ao patrimônio cultural, aos direitos humanos e dos povos” (ISA, 2015), indicam que os povos indígenas estão distribuídos nas diversas regiões do país, 
sendo uma parcela considerável a encontrar-se nas Terras Indígenas (246 povos), TIs, que atualmente somam 699, o que equivale a $13 \%$ do território nacional.

A Fundação Nacional do Índio alerta:

O contingente de brasileiros que se considerava indígena cresceu $150 \%$ na década de 90 . O ritmo de crescimento foi quase seis vezes maior que o da população em geral. O percentual de indígenas em relação à população total brasileira saltou de 0,2\% em 1991 para 0,4\% em 2000, totalizando 734 mil pessoas. Houve um aumento anual de $10,8 \%$ da população, a maior taxa de crescimento dentre todas as categorias, quando a média total de crescimento foi de $1,6 \%$ (FUNAI, 2015).

Apesar de tais dados, a expressar o crescimento da população indígena em desproporção (para mais) ao crescimento da população não indígena (para menos), a realidade demonstra que grande parte dos povos indígenas no Brasil vive em situação de vulnerabilidade social, seja pela não efetivação dos direitos constitucionais, seja pela ausência de políticas públicas voltadas às suas necessidades.

O reconhecimento dos povos indígenas pelo Estado a partir de 1988 enquanto primeiros habitantes da terra - povos originários - configura-se num grande avanço legal. Porém, tais grupos ainda vivem na invisibilidade social frente aos estereótipos e preconceitos construídos ao longo dos tempos, desde a colonização e que estão impregnados no termo “índio”. ${ }^{1}$ Em rótulos como "preguiçosos, bárbaros, selvagens, dentre outros termos que serviram para desqualificá-los” (RIBEIRO, 2015, p. 107) reside a problemática do imaginário social sobre os indígenas.

\footnotetext{
${ }^{1}$ Utilizam-se no presente trabalho as expressões "povos originários”, “índios”, “indígenas” e "populações indígenas" como sinônimos, para designar os diversos povos que já habitavam as terras no continente americano, antes da chegada dos europeus. Os termos "índios" e "indígenas", segundo os dicionários da língua portuguesa indicam "nativo" ou "natural de algum lugar". Os apelidos "índios" ou "indígenas" teriam sido equivocadamente dados por Cristóvão Colombo, durante uma expedição malsucedida frente a tempestades marítimas, acreditando ter chegado às Índias. Desde então, os diferentes povos nativos, independente de sua etnia, passaram a ser chamados de "índios".
}

Revista de Sociologia, Antropologia e Cultura Jurídica | e-ISSN: 2526-0251 | Maranhão | v. 3 | n. 2 | p. 45 - 65 | Jul/Dez. 2017. 
Certamente a partir de 1988 ocorre uma mudança de paradigma no tratamento jurídico destinado aos povos indígenas: da inferioridade para o reconhecimento. Não obstante, a lei por si só não muda a realidade social, pois as nações indígenas ainda não vivem a efetividade plena dos direitos assegurados. Por isso, o direito ao território configura-se essencial e fundamental para a realização da justiça social e promoção da dignidade da pessoa humana na coletividade indígena, em síntese: condição para a cidadania, uma vez que os elementos organização social, costumes, línguas, crenças e tradições só poderão se realizar no território, nas Terras Indígenas.

Para José Murilo de Carvalho (2012), na história do Brasil três empecilhos foram persistentes ao exercício da cidadania civil: a escravidão, que negava a condição humana do escravo; a grande propriedade rural, condicionada à ação da lei; e o Estado, comprometido com o poder privado. Carlos Frederico Marés de Souza Filho (1983), na reflexão sobre a cidadania indígena, já antes do advento da Constituição de 1988, afirmava que "ser o índio cidadão brasileiro, portanto, é uma ficção”, pois que os índios não construíram a nação brasileira, e para assumir tal condição, teriam que perder sua identidade, deixar de ser índio. Explicava que o índio cidadão, nesse período, o seria por naturalização.

Por sua vez, Marés afirmava que o índio, naquele contexto, enquanto mantivesse sua identidade cultural, pertenceria a uma nação diferente da brasileira, por exemplo, Guarani, Yanomami, Pataxó, entre as tantas etnias presentes no Brasil. Esse era o cenário de completa negação de direitos de cidadania em que viviam os povos originários nesse país, antes da Constituição de 1988, a Constituição Cidadã.

Atualmente, após 1988, a dúvida que se coloca passa por ponderar, “Índio Cidadão?”, como provoca o documentário, pois que embora o Estado tenha reconhecido os direitos aos povos indígenas; que estes foram os primeiros habitantes da terra e por isso, os direitos originários sobre as terras tradicionalmente ocupadas pelas populações; o direito a ser e permanecer índio em suas organizações sociais, manifestações culturais, costumes e tradições; 
a atual conjuntura e atuação do poder estatal (executivo, judiciário e legislativo) remete à dúvida quanto à efetividade da cidadania indígena.

O Relatório Violência contra povos indígenas no Brasil, dados de 2015, publicação do Conselho Indigenista Missionário (CIMI), alerta que em 2015 o governo da presidente Dilma Rousseff apresentou a menor média de homologações de terras indígenas desde o fim da ditadura militar, pois que:

Das 1.113 terras indígenas reconhecidas, em processo de reconhecimento pelo Estado brasileiro ou reivindicadas pelas comunidades, até agosto de 2016, apenas 398, ou 35,7\%, tinham seus processos administrativos finalizados, ou seja, foram registradas pela União (CIMI, 2015, p. 51).

Pelo referido relatório, a situação geral das Terras Indígenas no Brasil encontra-se conforme disposto no quadro abaixo:

\begin{tabular}{|c|c|c|}
\hline \multicolumn{3}{|c|}{ SITUAÇÃO GERAL DAS TERRAS INDÍGENAS NO BRASIL } \\
\hline SITUAÇÃO & QUANTIDADE & PORCENTAGEM \\
\hline REGISTRADAS & 398 & 35,75 \\
\hline HOMOLOGADAS & 15 & 1,34 \\
\hline DECLARADAS & 63 & 5,66 \\
\hline IDENTIFICADAS & 47 & 4,13 \\
\hline A IDENTIFICAR & 175 & 15,72 \\
\hline SEM PROVIDÊNCIAS & 348 & 31,35 \\
\hline COM RESTRIÇÃO & 6 & 0,53 \\
\hline RESERVADAS & 61 & 5,48 \\
\hline TOTAL & 1.113 & 100 \\
\hline
\end{tabular}

Fonte: CIMI, agosto de 2016.

Elaboração: Relatório Violência contra povos indígenas no Brasil, dados de 2015. 
Quando às categorias que identificam a "situação geral das Terras Indígenas no Brasil”, leia-se:

\begin{abstract}
Registradas (demarcação concluída e registrada no Cartório de Registro de Imóveis da Comarca e/ou no Serviço do Patrimônio da União); Homologadas (com Decreto da Presidência da República, e aguardando registro); Declaradas (com Portaria Declaratória do Ministério da Justiça, e aguardando a homologação); Identificadas (reconhecidas como território tradicional por Grupo Técnico da Funai, e aguardando Portaria Declaratória do Ministério da Justiça); A identificar (incluídas na programação da Funai para futura identificação, com Grupos Técnicos já constituídos); Sem providências (terras reivindicadas pela comunidade que ainda não constam na listagem da Funai para a realização de estudo); Com Restrição (terras que receberam Portaria da Presidência da Funai restringindo o uso da área ao direito de ingresso, locomoção ou permanência de pessoas estranhas aos quadros da Funai); Reservadas (demarcadas como "reservas indígenas" à época do SPI) ou Dominiais (de propriedade de comunidades indígenas) (CIMI, 2015, p. 51).
\end{abstract}

Ademais, um dado interessante trazido pelo mesmo relatório, refere-se ao número de homologações de terras por gestão presidencial:

- Presidente José Sarney (1985-1990) - 67;

- Presidente Fernando Collor de Melo (janeiro 1991-setembro 1992) - 112

- Presidente Itamar Franco (outubro 1992-dezembro 1994) - 18

- Presidente Fernando Henrique Cardoso (1995-2002) - 145

- Presidente Luis Inácio Lula da Silva (2003-2010) - 79

- Presidente Dilma Rousseff (2011-2015) - 18

Nesse documento, consta ainda um capítulo intitulado "Violência contra o patrimônio”, que apresenta os dados em três categorias: Omissão e morosidade na regularização de terras; Conflitos relativos a direitos territoriais; Invasões possessórias, | p. 45 - 65 | Jul/Dez. 2017. 
exploração ilegal de recursos naturais e danos diversos ao patrimônio. Dada à relevância, colaciona-se o gráfico a seguir:

\section{Capítulo I - Violência contra o patrimônio}

\begin{tabular}{|c|c|c|c|c|}
\hline UF & $\begin{array}{c}\text { Omissắo e } \\
\text { morosidade na } \\
\text { regularizaçăo de } \\
\text { terras }\end{array}$ & $\begin{array}{l}\text { Conflitos } \\
\text { relativos } \\
\text { a direitos } \\
\text { territoriais }\end{array}$ & \begin{tabular}{|c|} 
Invasóes \\
possessórias, \\
exploraçăo ilegal de \\
recursos naturais e \\
danos diversos ao \\
patrimônio \\
\end{tabular} & Total de Casos \\
\hline$A C$ & 17 & & & 17 \\
\hline AL & 8 & & 1 & 9 \\
\hline$A M$ & 180 & 1 & 6 & 187 \\
\hline BA & 15 & 2 & & 17 \\
\hline CE & 21 & & & 21 \\
\hline DF & 1 & & & 1 \\
\hline ES & 1 & & 1 & 2 \\
\hline Go & 1 & & & 1 \\
\hline MA & 9 & 1 & 18 & 28 \\
\hline MG & 11 & & & 11 \\
\hline MS & 96 & 10 & 2 & 108 \\
\hline MT & 42 & & 3 & 45 \\
\hline PA & 57 & & 12 & 69 \\
\hline
\end{tabular}

\begin{tabular}{|c|c|c|c|c|}
\hline UF & \begin{tabular}{c|} 
Omissä́o e \\
morosidade na \\
regularizaçáo de \\
terras
\end{tabular} & $\begin{array}{l}\text { Conflitos } \\
\text { relativos } \\
\text { a direitos } \\
\text { territoriais }\end{array}$ & \begin{tabular}{|c|} 
Invasóes \\
possessórias, \\
exploraçăo ilegal de \\
recursos naturais e \\
dan os diversos ao \\
patrim ônio
\end{tabular} & Total de Casos \\
\hline PB & 2 & & & 2 \\
\hline PE & 12 & & & 12 \\
\hline PI & 1 & & & 1 \\
\hline PR & 29 & & & 29 \\
\hline RJ & 7 & & & 7 \\
\hline RN & 1 & & & 1 \\
\hline RO & 27 & 2 & 5 & 34 \\
\hline $\mathbf{R R}$ & 3 & & 3 & 6 \\
\hline RS & 54 & 1 & & 55 \\
\hline SC & 18 & 1 & 2 & 21 \\
\hline SP & 34 & & 1 & 35 \\
\hline To & 7 & & 1 & 8 \\
\hline Total & 654 & 18 & 53 & 725 \\
\hline
\end{tabular}

Fonte: Relatório Violência contra povos indígenas no Brasil, dados de 2015. Elaboração: CIMI, 2015, p. 168.

Portanto, os dados apresentados reiteram as denúncias narradas no documentário e evidenciam que pensar a cidadania indígena passa necessariamente por considerar que a dignidade da pessoa humana, no caso da coletividade indígena, está relacionada à compreensão de ligação espiritual do indígena ao território. Ocorre que a lógica perversa das políticas de exploração econômica das terras e dos seus recursos naturais, travestidas como "políticas de desenvolvimento econômico" adotadas pelo Estado Brasileiro, acaba por desprezar os saberes e visões de mundo dos povos indígenas, colocando esses povos em situação de extrema vulnerabilidade social.

Para Ricardo Verdum (2016), a cidadania indígena surge num contexto de emergência das novas identidades, das reivindicações coletivas por direitos, pelo direito de "ser | p. 45 - 65 | Jul/Dez. 2017. 
diferente”. O antropólogo recorda que na atualidade dois instrumentos jurídicos internacionais respaldam a ideia de cidadania indígena: a Convenção 169 da Organização Internacional do Trabalho (OIT) e a Declaração das Nações Unidas sobre os Direitos dos Povos Indígenas.

No Brasil, o Decreto Legislativo n. 143 de 2002 aprova o texto da Convenção n. 169 da OIT e o Decreto n. 5.051 de 2004 a promulga. De acordo com a referida Convenção, a proteção ambiental das terras indígenas configura condição necessária para a sobrevivência dos povos indígenas enquanto grupos sociais distintos.

Por sua vez, a Declaração das Nações Unidas sobre os Direitos dos Povos Indígenas abarca em seu texto muitas das reivindicações dos povos indígenas na contemporaneidade, das mais diversas partes do mundo. Pode-se sintetizar alguns princípios contidos na Declaração: a igualdade de direitos e a proibição de discriminação; o direito à autodeterminação; a necessidade de fazer do consentimento e do acordo de vontades o fundamento das relações entre povos indígenas e os Estados.

O Brasil se manifestou favorável à Declaração na Assembleia da Organização das Nações Unidas, logo não há necessidade da existência de lei ou da ratificação do Congresso Nacional para a aplicação da Declaração no âmbito interno. Observa-se, no entanto, que seria oportuno se no caso brasileiro fossem aprovadas novas leis sobre os direitos indígenas e as relações com o Estado, a fim de aprimorar o reconhecimento inaugurado pela Constituição de 1988 e então efetivar direitos, tal como o Projeto de Lei do Estatuto das Sociedades Indígenas, paralisado há anos no Congresso.

Não restam dúvidas que o direito às terras tradicionalmente ocupadas pelos índios, reiterado na Declaração da ONU em 2007, apresenta-se como um dos pontos polêmicos para a efetivação da cidadania indígena no Brasil, frente à cultura ocidental capitalista que continua a imperar, quase que nos mesmos moldes desde a colonização, na realidade conturbada do Estado e daquelas forças sociais visivelmente anti-indígenas.

Logo, o uso da fonte cinematográfica para a pesquisa no direito juntamente com a pesquisa documental e bibliográfica, pode propiciar análises que podem romper com a visão | p. 45 - 65 | Jul/Dez. 2017. 
tradicional e colonialista herdada no pensamento científico brasileiro, especialmente quanto ao tema dos povos originários. Os povos indígenas vêm utilizando o cinema enquanto manifestação artística, usufruindo o recurso da oralidade (tão presente na cultura indígena) através da narrativa audiovisual, o que permite perceber essas realidades e suas visões do mundo. Essa sensibilização é oportuna no direito para que se possa obter uma reflexão crítica, rompendo com os estereótipos e preconceitos históricos e culturais a despeito dos distintos grupos étnicos que compõe a realidade multicultural brasileira.

\section{CONCLUSÃO}

Diante da abordagem estabelecida, que utilizou o documentário “Índio Cidadão?” para análise, conclui-se que tais povos, embora os avanços legais com a Constituição de 1988, permanecem na "invisibilidade" social, ante a cultura dominante estabelecida, sofrendo constantes violações de direitos. Nesse contexto, o cinema se configura como documento da área da comunicação que permite mostrar a realidade do(s) povo(s) através da narrativa, ao atingir de uma só vez número significativo de pessoas. O cinema ao sensibilizar apresenta-se enquanto recurso inovador e essencial para (re)pensar o direito, a metodologia no ensino do direito, o direito nas instituições do Estado Democrático, visando a construção de um direito que inclua as diversas e distintas realidades sociais.

Dessa forma, a pesquisa no direito deve estar aberta a trabalhar com outras fontes e categorias a partir dessas, tal como a fonte cinematográfica, que possibilita a pesquisa empírica e uma maior aproximação da(s) realidade(s). O estudo do direito nessa perspectiva crítica se apresenta enquanto alternativa ao positivismo, não devendo se restringir a teorizar, ou simplesmente criticar o direito posto. Almeja-se, por outro lado, a busca de um direito que

Revista de Sociologia, Antropologia e Cultura Jurídica | e-ISSN: 2526-0251 | Maranhão | v. 3 | n. 2 | p. 45 - 65 | Jul/Dez. 2017. 
na prática corresponda ao que socialmente se almeja. E no tocante ao tema dos povos originários tal perspectiva parece fundamental para modificar a cultura dominante acerca do lugar do índio na sociedade brasileira, a situação de vulnerabilidade social em que se encontram tais coletividades, conforme análise desenvolvida ao longo da presente pesquisa.

Enfim, o documentário “Índio Cidadão?”, enquanto fonte para estudo e reflexão do direito, evidencia que, embora pouco lembrada na história, a participação dos grupos indígenas na Assembleia Constituinte de 1987, foi fundamental para o reconhecimento das garantias asseguradas na Constituição Federal de 1988. E que, ao longo dos anos de vigência da referida Constituição, que reconhece a cidadania aos povos, lamentavelmente tais grupos continuam à margem do Estado, pois que vivenciam, na prática, graves violações de direitos humanos. Logo, para efetividade da cidadania indígena, ao Estado cabe a manutenção e o cumprimento das medidas cabíveis para a demarcação das terras indígenas e demais políticas voltadas à sobrevivência sociocultural dos povos originários.

\section{REFERÊNCIAS}

ARAÚJO, Ana Valéria. Terras Indígenas no Brasil: retrospectiva, avanços e desafios do processo de reconhecimento. In: FANY, Ricardo (Org.). Terras Indígenas e Unidades de Conservação da Natureza: o desafio das superposições. São Paulo: Instituto Socioambiental, 2004. p. 26-36.

BRASIL. Lei n. 6.001, de 19 de dezembro de 1973. Disponível em: <http://www.planalto.gov.br/ccivil_03/leis/l6001.htm>. Acesso em: 10 mar. 2015.

BRASIL. Constituição da República Federativa do Brasil. 1988. Disponível em: < http://www.planalto.gov.br/ccivil_03/constituicao/constituicaocompilado.htm>. Acesso em: 10 mar. 2015.

BRASIL. Proposta de Emenda à Constituição n. 215, de 28 de março de 2000. Disponível em: < http://www.camara.gov.br/proposicoesWeb/fichadetramitacao?idProposicao=14562>. Acesso em: 09 ago. 2017. | p. 45 - 65 | Jul/Dez. 2017. 
BUZATTO, Cleber César. A paralisação das demarcações como elemento indutor da violência. In: RANGEL, Lúcia Helena et al (Coords.). Relatório Violência contra os Povos Indígenas no Brasil - Dados de 2013. Brasília: Editora Conselho Indigenista Missionário, 2013. p. 11-14.

CARVALHO, José Murilo de. Cidadania no Brasil: o longo caminho. 3. ed. Rio de Janeiro: Civilização Brasileira, 2012.

COHN, Sergio (Org.). Encontros: Ailton Krenak. Rio de Janeiro: Azougue, 2015. (Coleção Encontros).

CONSELHO INDIGENISTA MISSIONÁRIO. Relatório Violência contra os Povos Indígenas no Brasil - Dados de 2015. Coordenado por Lúcia Helena Rangel e outros. Brasília: Editora Conselho Indigenista Missionário, 2015.

DALLARI, Dalmo de Abreu. Terras indígenas: a luta judicial pelo direito. In: Conselho Indigenista Missionário Regional Mato Grosso do Sul, Comissão Pró Índio de São Paulo, Procuradoria Regional da República $3^{\text {a }}$ Região (Org.). Conflitos de Direitos Sobre as Terras Guarani Kaiowá no Estado do Mato Grosso do Sul. São Paulo: Palas Athena, 2000. p. 3137.

FUNDAÇÃO NACIONAL DO ÍNDIO. Quem sabe. Disponível em: <http://www.funai.gov.br/index.php/indios-no-brasil/quem-sao>. Acesso em: 25 out. 2015.

“ÍNDIO CIDADÃO?”. Direção: Rodrigo Siqueira Arajeju; Produção: Isadora Stepanski. Distrito Federal: 7G DOCUMENTA, 2014. 1 DVD (52 min). . Disponível em: < https://indiocidadao.org/>. Acesso em: 07 ago. 2017.

INSTITUTO BRASILEIRO DE GEOGRAFIA E ESTATÍSTICA. In: Indígenas. Gráficos e Tabelas. Disponível em: < http://indigenas.ibge.gov.br/graficos-e-tabelas-2>. Acesso em: 10 mar. 2015.

INSTITUTO SOCIOAMBIENTAL. In: Terras Indígenas. Localização e extensão das TIs. Disponível em: <http://pib.socioambiental.org/pt/c/terras-indigenas/demarcacoes/localizacaoe-extensao-das-tis>. Acesso em: 10 mar. 2015.

KRENAK, Ailton. Discurso na Assembleia Nacional Constituinte. In: COHN, Sergio (Org.). Encontros: Ailton Krenak. Rio de Janeiro: Azougue, 2015. p. 32-35. (Coleção Encontros).

Revista de Sociologia, Antropologia e Cultura Jurídica | e-ISSN: 2526-0251 | Maranhão | v. 3 | n. 2 | p. 45 - 65 | Jul/Dez. 2017. 
Receber Sonhos. In: COHN, Sergio (Org.). Encontros: Ailton Krenak. Rio de Janeiro: Azougue, 2015. p. 80-113. (Coleção Encontros).

O eterno retorno do encontro. In: COHN, Sergio (Org.). Encontros: Ailton Krenak. Rio de Janeiro: Azougue, 2015. p. 160-167. (Coleção Encontros).

MARÉS DE SOUZA FILHO, Carlos Frederico. A cidadania e os índios. In: COMISSÃO PRÓ-ÍNDIO. O índio e a cidadania. São Paulo: Editora Brasiliense, 1983. p. 44-51.

RIBEIRO, Núbia Braga. Políticas Públicas e os Povos Indígenas no Brasil Contemporâneo. In: RESENDE, Maria Leônia Chaves de (Org.). Mundos Nativos: Culturas e história dos povos indígenas. Belo Horizonte: Fino Traço, 2015, p. 107-143.

VERDUM, Ricardo. Cidadania Indígena. In: SIDEKUM, Antonio; WOLKMER, Antonio Carlos; RADAELLI, Samuel Manica (Orgs.). Enciclopédia Latino-Americana dos Direitos Humanos. Blumenau: Edifurb. Nova Petrópolis: Nova Harmonia, 2016, p. 86-91. | p. 45 - 65 | Jul/Dez. 2017. 